\title{
The association between statin-use and diet, exercise, and perceptions of high cholesterol in urban and semi-urban Nigerians: a cross-sectional study.
}

Joyce F Coker ( $\nabla_{\text {jfc44@medschl.cam.ac.uk ) }}$

University of Cambridge https://orcid.org/0000-0001-6378-8841

Kate M Hill

Leeds Institute of Health Sciences

Akaninyene A Otu

University of Calabar Teaching Hospital

Allan House

Leeds Institute of Health Sciences

Research article

Keywords: Statins, Diet, Physical activity, Hyperlipidaemia, Common Sense Model, Health belief model, Urbanisation, Nigeria

Posted Date: September 2nd, 2019

DOI: https://doi.org/10.21203/rs.2.13851/v1

License: (c) (1) This work is licensed under a Creative Commons Attribution 4.0 International License.

Read Full License 


\section{Abstract}

Background The rise of cardiovascular diseases in sub-Saharan Africa strains fragile healthcare systems. Cardiovascular disease prevention involves the use of prophylactic medications like statins and the adoption of healthy lifestyle choices. However, the nature of the relationship between statin-use and the adoption of healthy lifestyle choices remains unclear. This study is the first to examine whether there is a relation between statin-use, the adoption of a low-fat diet and healthy exercise behaviours, and the way Nigerians diagnosed with hyperlipidaemia think about high cholesterol as a risk factor for cardiovascular disease. Methods This cross-sectional study was conducted in an urban site and a semi-urban site in Nigeria. Questionnaires were used to compare the dietary and exercise behaviours; perceptions of high cholesterol; and perceived future risk of cardiovascular disease of 78 statin users and 70 non-statin users. Results The majority (69\%) of participants reported that they had adopted a low-fat diet. However, $80 \%$ participants were classified as inactive/moderately inactive and statin users were significantly less active than non-statin users ( $86 \%$ of statin users inactive/moderately inactive vs $74 \%$ of non-statin users, $X 2=3.852, p=0.05$ ). A logistic regression model found that odds of adopting a low-fat diet was 5 times greater in participants recruited from the urban research site $(95 \% \mathrm{Cl}=1.7$ to $12.5, \mathrm{p}=0.003)$ and increased as reported perceived statin control of high cholesterol increased ( $\mathrm{OR}=2.33,95 \% \mathrm{Cl}=1.16$ to 4.69 , $p=0.018$ ). Conclusions The odds of adopting a low-fat diet increased as statin control perceptions increased - suggesting that statin-use and the adoption of healthy dietary choice were thought to work in unison to manage high cholesterol. Urban-dwellers were more likely to have adopted healthy dietary choices and to think about adopting exercise choices than semi-urban dwellers. This demonstrates a growing awareness of negative future impacts of Westernised lifestyle behaviours in urban areas and the need for public health interventions in semi-urban areas to raise awareness and facilitate the adoption of healthy lifestyle choices in order to curtail the rise of cardiovascular disease in Nigeria.

\section{Introduction}

Developing countries in sub-Saharan Africa face a double burden of non-communicable and communicable disease. The latter is still the major cause of adult mortality in the region, but noncommunicable diseases pose a substantial burden and appear to be on the rise, further straining already over-burdened and fragile health care systems (1-3). In Nigeria, non-communicable diseases are thought to account for $29 \%$ of adult deaths, $11 \%$ of which are due to cardiovascular disease (4).

The rise of cardiovascular diseases and other non-communicable diseases in sub-Saharan Africa has been attributed to an aging population and urbanisation (5-9). A key strategy for the primary prevention of cardiovascular disease is the lowering of lipid levels $(2,10)$. This can be done by making lifestyle modifications such as eating a low-fat diet, regular physical activity and smoking cessation. Where needed, lipid-lowering medications such as statins are prescribed for use alongside lifestyle modifications (10-12). Due to their documented effectiveness in lipid modification, statins have become the medication of choice and one of the most prescribed medications in the world. However, there remains some doubt about their benefit for the primary prevention of cardiovascular disease where even 
relatively low rates of side effects may not be justified by their effect on preventing uncommon events (13-15).

There is sparse and conflicting data available on the relationship between statin-use and the adoption of healthy lifestyle choices (16). Some researchers claim that statin-use provides a false sense of security, enabling people to neglect lifestyle modifications and continue to make poor lifestyle choices (17-19). Others have either found no difference or found that statin users consumed less dietary fat than nonstatin users $(16,20)$. As statin-use increases, it is important to assess whether there is an interaction between statin-use and the adoption of healthy lifestyle choices for a variety of reasons. Firstly, whilst research confirms that statins produce a moderate reduction in cardiovascular disease risk, their effect is enhanced when combined with lifestyle modifications (21-23). Secondly, these lifestyle modifications are beneficial not only for the control of lipid levels but also for the control of other cardiovascular disease risk factors, non-communicable diseases, and promote overall health and wellbeing (7).

Understanding factors that influence modifiable health-related behaviours such as the adoption of healthy lifestyle choices may facilitate the development and implementation of targeted public health interventions. $(2,24-26)$. This could potentially help curb the rise of cardiovascular disease risk factors in sub-Saharan Africa.

We have not identified any studies that investigate the relation between statin-use and the adoption of healthy lifestyle choices in sub-Saharan Africa where the burden of cardiovascular disease risk factors is on the rise. Consequently, this study aimed to examine whether there is a relation between statin-use, the adoption of a low-fat diet and healthy exercise behaviours.

We were also interested in the way Nigerians diagnosed with hyperlipidaemia think about high cholesterol as a risk factor for cardiovascular disease. We used the Common Sense Model of self-regulation, and the Health Belief Model as frameworks to understand how illness perceptions and health beliefs influence health-related behaviours (24, 27-29). The Common Sense Model posits that when faced with a health threat, individuals produce a cognitive representation of the health threat which informs their choice of coping strategies (29). The Health Belief Model was originally developed to explain or predict preventive health behaviours in healthy individuals and to detect disease in asymptomatic individuals (28).

\section{Methods}

\section{Study design and setting}

This cross-sectional study was conducted between August to October 2013 in two medical practices in Nigeria. The first site was the Nigeria National Petroleum Corporation (NNPC) medical services located in the cosmopolitan Maitama district in Abuja, Nigeria. NNPC is a national oil and gas company and provides free healthcare for its staff and their immediate family. Abuja is the capital of Nigeria and has been exposed to a lot of Western influences. This site will be referred to as the urban research site. The second site was University of Calabar Teaching Hospital (UCTH) located in Calabar, the capital of Cross- 
Rivers state in the oil-rich Niger delta region. Tourism has become an alternative main avenue of wealth creation for Cross-River state (30). Consequently, Cross River state is rapidly undergoing urbanisation (31). This site will be referred to as the semi-urban research site.

Ethical approval was obtained from the Nigerian Institute for Medical Research and from local research ethics committees of both research sites.

\section{Study sample}

Inclusion criteria

- Adults aged $\geq 18$ years

- Recorded diagnosis of hyperlipidaemia and

- Attended a hospital appointment at either site during the study period

\section{Exclusion criteria}

- Not of Nigerian origin

- Did not speak English

- Individuals who had experienced a diagnosed cardiovascular event were excluded in order to focus on primary prevention of cardiovascular disease.

- Individuals who had a diagnosis of familial hypercholesterolemia or type 1 diabetes due to role of genetics in these conditions.

- Individuals diagnosed with HIV were excluded because research suggests that HIV and the use of highly active antiretroviral therapy may cause metabolic disruptions that lead to dyslipidaemias, hypertension and insulin resistance (32).

\section{Measures}

\section{Demographics and cardiovascular disease risk factors}

A structured questionnaire was used to elicit demographic information from participants.

A medical diagnosis of diabetes, hypertension and statin-use at the time of the study were obtained from medical records. This information was also confirmed by participants prior to the administration of the questionnaire.

Participants who were taking a statin at the time of this study were classified as statin users. Non-statin users, included participants who had not been prescribed a statin and participants who had previously been prescribed a statin but were not taking a statin at the time of the study. 


\section{Dietary patterns}

Questions about the consumption of fried foods and the use of cooking oil from the European Prospective Investigation of Cancer and Nutrition (EPIC) food frequency questionnaire were included in the study questionnaire to elicit information about the dietary fat consumption of participants $(33,34)$. The options of cooking oil in the study questionnaire were altered to reflect the Nigerian diet.

The questionnaire also included questions to assess reduction in dietary fat consumption using Prochaska and DiClemente's model of dietary change. Participants classified by this model as belonging to either the pre-contemplation, contemplation or decision stages of change were regarded as nonadopters of a low-fat diet. Participants in the action or maintenance stages of change were regarded as adopters of a low-fat diet (35).

\section{Exercise patterns}

Questions from the UK Department of Health's General Practice Physical Activity Questionnaire (GPPAQ) were used to assess participants' level of physical activity and classify them as either: inactive, moderately inactive, moderately active or active (36). Questions adapted from Prochaska and Diclemente's model of dietary change were used to classify participants in the pre-contemplation, contemplation, decision stages of change as non-adopters of healthy exercise behaviours. Participants in the action and maintenance stages were regarded as adopters of healthy exercise behaviours (35).

\section{Perception of high cholesterol}

The Revised Illness Perception Questionnaire (IPQ-R) was used to assess the cognitive representations of and emotional responses to high cholesterol among study participants (37). The IPQ-R is a 5-point Likert scale ( 1 = strongly disagree to 5 = strongly agree) that contains subscales derived from the Common Sense Model of self-regulation. High scores on the included sub-scales indicate a strong emotional response; limited understanding of high cholesterol (illness coherence); the belief that high cholesterol is chronic (timeline), unpredictable (timeline cyclical); has serious consequences or affects quality of life (consequences); and can be controlled by statin-use (statin control) or personal efforts (personal control) $(24,27,38)$. The identity or symptom sub-scale was not included in this study because high cholesterol is asymptomatic (27). Two items "spiritual causes" and "fate/destiny" were added to the cause subscale of the IPQ-R because religion plays a major role in the way Nigerians perceive the world around them and make sense of illness, death and suffering (39).

\section{Perception of future risk of cardiovascular disease}

Champion's Health Belief Model Scale was used to assess the participants' beliefs about their risk of cardiovascular disease (40). High scores on these 5 -point Likert scales ( $1=$ strongly disagree to $5=$ 
strongly agree) indicate: a perceived susceptibility to heart disease; the perception that heart disease is a serious health threat; the perception that statin-use or adopting healthy lifestyle choices is beneficial (perceived benefits); and the perception that there are a lot of barriers to statin-use or the adoption of healthy lifestyle choices (perceived barriers). The health motivation sub-scale was not included in this study as it is not one of the 4 core components of the health belief model $(28,41)$.

To ensure that the questionnaire was understandable and culturally acceptable, it was piloted on 10 Nigerians aged between 27-65years olds.

\section{Data collection}

Consecutive patients who attended either site and met the study inclusion criteria as determined by medical staff using a screening questionnaire were approached by the researcher in the waiting room. The study was explained and an information sheet was given to potential participants. The researcher verbally went through the information sheet and obtained consent prior to the administration of the questionnaires. In the semi-urban site, all questionnaires were researcher administered. In the urban site, participants were given the option have their questionnaires administered by the researcher or to selfadminister their questionnaires and return them to the researcher or clinical staff in a sealed envelope at their convenience.

\section{Data analysis}

All data entry and analysis was carried out using the Statistical Package for the Social Sciences (SPSS) version 20. A mean scores were calculated for each of the sub-scales in the IPQ-R and Champion's Health Belief Model Scale $(37,40)$. In accordance with the instructions for the IPQ-R, the total score and not mean score of each cause subscale was calculated (37).

The Normality of the distribution of continuous variables was assessed and mean scores and standard deviations were calculated when data were Normally distributed; frequencies were calculated for categorical variables. Independent t-tests or Mann-Whitney tests were used to assess between group differences in continuous variables. Chi-square tests or Fisher's exact tests were used to assess between group differences in categorical variables.

Logistic regression models were used to identify variables that were associated with the adoption of a low-fat diet and the adoption of healthy exercise choices. Using Green's rules, it was calculated the minimum sample size required for a logistic regression model containing 8 variables was 114 participants (42). For all statistical tests, $\mathrm{p}<0.05$ was taken as the level of statistical significance.

\section{Results}




\section{Participant characteristics}

The overall sample consisted of 78 (53\%) statin users and $70(47 \%)$ non-statin users. As shown in Table 1, participants were predominantly females (57\%) and were aged between $40-69 y e a r s ~(84 \%)$. The mean age of the sample was 52.9 years $(S D=11.11)$. Most participants had hypertension $(60 \%)$ and a quarter (24\%) had hypertension and diabetes.

Over half (55\%) of participants were recruited from the semi-urban site. Although not statistically significant, statin-use was more common in the urban site than in the semi-urban site $\left(59 \%\right.$ vs $48 \%, X^{2}=$ $1.950, p=0.187$ ). Urban dwellers were significantly better educated (tertiary education $=79.4 \%$ urban dwellers vs $38.3 \%$ semi urban dwellers, Fisher's exact $=41.14, p<0.001)$, more likely to be male $(O R=3.3$, $\left.X^{2}=12.190, p=0.001\right)$, married $(O R=1.7$, Fisher's exact $=8.63, p=0.031)$, and have lived outside of Nigeria in the 10-years prior to this study than semi-urban dwellers $\left(O R=7.5, X^{2}=12.72, p<0.001\right)$. Significantly fewer urban dwellers had diabetes $\left(33.3 \%\right.$ vs $\left.56.9 \%, X^{2}=6.79, p=0.011\right)$ and were from Cross-Rivers state $(4.7 \%$ vs $90.2 \%$, Fisher's exact $=126.116, p<0.001)$.

$<$ Insert Table 1: Characteristics of the study sample>

\section{Dietary patterns}

Most participants (76\%) reported that they consumed fried foods at home on a weekly basis, while only $35 \%$ reported doing so away from their homes. As shown in Table 2, $69 \%$ of participants reported that they had adopted a low-fat diet. Over half of these participants (59\%) had been doing so for a least a year prior to the study. Statin and non-statin users did not significantly differ in their reported adoption of a low-fat diet or any other reported dietary behaviours.

Urban dwellers were significantly more likely to report that they consumed of fried foods on a weekly basis that semi-urban dwellers ( $65 \%$ vs $\left.91 \%, X^{2}=15.61, p<0.001\right)$. The odds of reporting the consumption of fried foods outside the home was 16 times higher in urban dwellers than in semi-urban dwellers $(11 \%$ vs $65 \%$, Fisher's exact $=51.41, p<0.001)$. Nevertheless, the odds of reportedly adopting a low-fat diet was 6 times higher in urban dwellers than in semi-urban dwellers ( $55 \%$ vs $\left.86 \%, X^{2}=18.30, p<0.001\right)$. They were also significantly more likely to reportedly think they were eating a low-fat diet than semi-urban dwellers (44\% vs $\left.80 \%, X^{2}=21.90, p<0.001\right)$.

$<$ Insert Table 2- Dietary patterns $>$

\section{Exercise patterns}

As shown in Table 3, majority of participants (80\%) were classified as inactive/moderately inactive; most reported that they had never increased the frequency or intensity of their exercise (78\%); and were 
classified as non-adopters of healthy exercise behaviours at the time of the study (85\%).

Statin users were significantly less active than non-statin users ( $86 \%$ of statin users were inactive/moderately inactive vs $74 \%$ of non-statin, $X^{2}=3.852, p=0.05$ ).

Urban and semi-urban dwellers did not significantly differ in their levels of physical activity or reported adoption of healthy exercise behaviours. However, significantly more urban dwellers reported that they had at some point in time, increased their frequency or intensity of exercise (OR $=2.5,30 \%$ vs $15 \%, X^{2}=$ $5.30, p=0.027$ ). Urban dwelling non-adopters were also 15 times more likely to report that they had considered adopting healthy exercise behaviours in the previous month than semi-urban dwelling nonadopters $\left(48 \%\right.$ vs $\left.6 \%, X^{2}=30.00, p<0.001\right)$.

$<$ Insert Table 3- Exercise patterns $>$

\section{Perception of high cholesterol}

As shown in Table 4, participants reportedly believed their high cholesterol could be controlled by their own behaviours (mean personal control score $=3.9, S D=0.62$ ) and by taking a statin (mean statin control score $=3.7, S D=0.64)$. However, reported perceptions of the former were stronger than perceptions of the latter. Correspondingly, the most important cause of high cholesterol reported by participants was lifestyle causes, followed by biomedical causes. The low score obtained on the timeline acute/chronic subscale, indicates that participants perceived their high cholesterol as an acute condition (mean timeline acute/chronic score $=2.2, \mathrm{SD}=0.66$ ).

Both statin users and non-statin users reported stronger perceptions of personal control than statin control of high cholesterol. This indicates that both groups reportedly believed that their behaviours could control their high cholesterol better than statin-use. However, statin users reported significantly stronger statin control perceptions than non-statin users (3.8 vs $3.6, U=1721.500, p=0.003$ ).

Urban dwellers reportedly thought that they had a poor understanding of high cholesterol compared to semi-urban dwellers (mean illness coherence, 3.6 vs $2.9 \mathrm{U}=1497.000, p<0.001$ ). They also reported significantly stronger perceptions that high cholesterol is an acute condition (mean timeline acute/chronic, 2.0 vs $2.4 U=1587.500, p<0.001$ ), but they perceived it to be less predictable i.e. less cyclical than semi-urban dwellers (mean timeline cyclical, 2.9 vs $3.4, U=1626.500, p=0.002$ ).

\section{Perception of future risk of cardiovascular disease}

As shown in Table 5, participants reportedly perceived healthy lifestyle choices (mean perceived benefits of lifestyle choices, $4.00 \mathrm{SD}=0.65$ ) to be more beneficial than statin-use for the prevention of cardiovascular disease (mean perceived benefit of statin-use, $3.8 \mathrm{SD}=0.70$ ). However, they thought they were more barriers to making healthy lifestyle choices than to taking a statin. The low score obtained on 
the perceived susceptibility sub-scale indicates that participants did not perceive themselves to be at risk of cardiovascular disease $(2.4, \mathrm{SD}=0.83)$.

Statin users reportedly perceived significantly fewer barriers to statin-use for cardiovascular disease prevention ( 2.3 vs $2.6, U=1715.000, p=0.027$ ), and perceived cardiovascular disease to be significantly more severe than non-statin users ( $3.1 \mathrm{vs} 2.9, \mathrm{U}=1745.500, \mathrm{p}=0.040$ ).

Urban dwellers reportedly perceived cardiovascular disease to be significantly more severe than semiurban dwellers ( 3.2 vs $2.8, U=1707.500, p=0.027$ ). They also thought they were fewer barriers to $(2.0 \mathrm{vs}$ $2.8, U=1815.000, p=0.840$ ) and significantly more benefits of the adoption of healthy lifestyle for cardiovascular disease prevention than semi-urban dwellers ( 4.1 vs $3.9, U=1635.500, p=0.007$ ).

\section{Factors associated with the adoption of a low-fat diet}

Of the 148 participants recruited, $128(86 \%)$ completed all sections of the questionnaire that were entered into a logistic regression model where the dependent variable was adoption of a low-fat diet and independent variables were: statin-status; gender; research site; physical activity level; perceived statin control of high cholesterol; perceived barriers to statin-use for cardiovascular disease prevention; and perceived severity of cardiovascular disease.

The logistic regression model was statistically significant $\left(X^{2}=25.822, p=0.001\right)$ and correctly classified $73 \%$ of cases. The model explained between $18.3 \%$ (Cox and Snell $\mathrm{R}^{2}$ ) and $26.0 \%$ (Nagelkerke $\mathrm{R}^{2}$ ) of variance in the adoption of a low-fat diet and the Hosmer and Lemeshow test of fit indicated that the model was a good fit to the data $\left(X^{2}=6.00, p=0.647\right)$.

As shown in Table 6, only research site and perceived statin control of high cholesterol made statistically significant contributions to the model. The odds of adopting a low-fat diet was 5 times greater in participants recruited from the urban research site and increased as reported perceived statin control of high cholesterol increased. The model assessing factors associated with the adoption of healthy exercise behaviours was not statistically significant $\left(X^{2}=9.674, p=0.378\right)$ and will not be presented in this article.

\section{Discussion}

This study aimed to examine whether there is a relation between statin-use, the adoption of a low-fat diet and healthy exercise behaviours, and the way Nigerians diagnosed with hyperlipidaemia think about high cholesterol as a risk factor for cardiovascular disease.

\section{Statin use and diet}

The majority of respondents reported dietary changes. We found that statin-use was not on its own associated with the adoption of a low-fat diet. This is in accordance with the findings of three American 
studies $(16,17,43)$. However, despite finding no significant differences in the dietary fat intake of statin users and non-statin users, one of the aforementioned American studies did find that statin users consumed significantly fewer fruits, vegetables and vitamins. This led the authors to conclude that statinuse negatively influenced healthy dietary behaviours (43). This is in contrast with the findings of our own study and the findings of two of previously the American studies.

\section{Physical activity}

By contrast with our findings on diet, the majority of the participants in the present study were physically inactive/moderately inactive, had not adopted healthy exercise choices at the time of the study, and had not considered doing so in the month prior to the study. The poor physical activity behaviours we observed are consistent with the findings from the Nigerian Heart Foundation survey and a study conducted in Uyo, Cross Rivers' neighbouring state. Ekpenyong et al and the Nigerian Heart Foundation survey found that the majority of Nigerians their studies engaged in fewer than 30-minutes of moderateintensity physical activity at least 5 times a week $(3,44)$. It should be noted that the data on physical activity in Nigeria are limited and the studies which are available define and assess physical activity differently (45), making it difficult to compare across studies and yielding a wide range of the prevalences of physical inactivity in Nigeria.

\section{Healthy diet and exercise}

Despite having adopted healthy dietary choices, the majority of participants in this study had not adopted or thought about adopting healthy exercise behaviours. Many researchers have voiced the need to pay more attention to and encourage the adoption of healthy exercise behaviours for cardiovascular disease prevention, non-communicable disease prevention and to promote overall health (46). The preference for adopting healthy dietary choices but not healthy exercise choices in this study may have resulted from the attribution of high cholesterol to dietary factors not physical inactivity. Alternatively, the preference may have occurred because malnutrition is and has been a major issue in Nigeria (47) leading to more attention being paid to dietary choices than to exercise choices. Furthermore, the increased use of technology, improvements in transportation, and the insecurity in some parts of Nigeria may limit outdoor activities. A lack of gyms, sports clubs, playgrounds, swimming pools and other exercise-enabling infrastructure may also hinder the adoption of healthy exercise choices and contribute to the high levels physical inactivity identified in this study (48).

\section{Statin use and exercise}

A significantly high proportion of the statin-users in this study were inactive/moderately inactive compared to non-statin users. This suggests that although statin-use appeared to be unrelated to dietary behaviours, it may have encouraged physical inactivity. This may have occurred because majority of 
statin users had adopted a low-fat diet, therefore, they may have felt that statin-use alongside the adoption of a low-fat diet were adequate strategies to control their high cholesterol, allowing them to neglect the adoption of healthy exercise. The increased physical inactivity found among the statin users in this study contrasts with the findings of two American studies and one Swedish study. The American studies both found no difference in the physical activity levels of statin users and non-statin users (16, 43). The Swedish study found significantly healthier exercise behaviours among statin users than among non-statin users (20). However, it should be noted that majority of the non-statin users in the Swedish study did not have high cholesterol. Furthermore, they were younger and had a significantly lower cardiovascular disease risk profile than statin users. Consequently, they were a poor comparison group for the Swedish statin users who as a result of their poor health, may have been exposed to more lifestyle advice and may have a stronger perception of the consequences of high cholesterol because they had experienced more cardiovascular events. Thus may have been more likely to adopt health lifestyle behaviours than their non-statin comparators (20).

\section{Thinking about risk}

We also aimed to explore whether there is a relation between statin-use and the way Nigerians diagnosed with hyperlipidaemia think about their high cholesterol as a risk factor for cardiovascular disease. Statin users in this study perceived significantly fewer barriers to statin-use for cardiovascular disease prevention than non-statin users. This may be because more of the statin users in this study were recruited from the urban site where healthcare and medication is free. Statin-users also perceived cardiovascular disease to be more severe than non-statin users. This is in accordance with existing research which suggests that the initiation of statin-use may increase risk perception $(16,20)$.

Although this study found that statin-use in itself did not influence the adoption of a low-fat diet; the odds of adopting a low-fat diet was found to increase as perceived statin control of high cholesterol increased. This finding, and the closeness in the mean scores for perceived statin control and perceived personal control of high cholesterol, suggests that the statin users in this study thought that statin-use and the adoption of healthy lifestyle choice (predominantly dietary choices) work in unison to manage high cholesterol.

The reasons for perceiving a synergistic relationship between statin-use and the adoption of healthy lifestyle choices remains unknown (20). However, research cites three possible explanations. Firstly, the prescription of a statin may increase risk perception and serve as a wake-up call that facilitates the adoption of healthy lifestyle choices $(16,20)$. The second possible explanation is that the general dislike for medication-use, or concerns about long-term medication-use may encourage the adoption of both medical and lifestyle control strategies in an attempt to lower cholesterol and cease medication-use (16). The third explanation is that lifestyle changes were initiated at the same time as statin-use. This may have resulted from statin initiation serving as a wake-up call, or simply because both control strategies were prescribed at the same time (16). 


\section{Urban and semi-urban living and lifestyle}

The biggest differences in the adoption of healthy lifestyle choices, perceptions of high cholesterol, and perceptions of future cardiovascular disease risk in this study occurred between urban dwellers and semiurban dwellers. The findings that urban dwellers were significantly more likely than semi-urban dwellers to consume fried foods and eat outside of the home on a weekly basis suggests that the urban dwellers in this study were more exposed to Western diets and had acquired more unhealthy lifestyle behaviours than semi-urban dwellers. Several studies have documented a rise in the prevalence of non-

communicable disease risk factors in urban areas as a result the adoption of Western lifestyle behaviours fuelled by rural-to-urban migration for work and urbanisation $(2,3,8,49,50)$.

The urban dwellers in this study perceived their future cardiovascular disease risk to be more severe, and perceived the adoption of healthy lifestyle choices for the prevention of cardiovascular disease to be more beneficial than semi-urban dwellers. This may indicate that urban dwellers were more aware of the negative future impacts of their westernised lifestyle behaviours and were actively trying to adopt healthy lifestyle choices. Urban dwellers may also have more facilities and resources available that facilitate the adoption of healthy lifestyle choices than semi-urban dwellers as rural-to-urban migration by working-age adults limits the resources available in semi-urban and rural populations (50).

Finally, it should be noted that participants in this study perceived high cholesterol to be an acute condition. A possible explanation for this may be that chronic illness are still relatively new in nonWesternised countries like Nigeria where the epidemiological transition from communicable to noncommunicable disease is underway $(51-53)$. This highlights the need for health education about noncommunicable disease risk factors and the healthy lifestyle choices.

\section{Study limitations}

This study was cross-sectional in nature, therefore it is important to remember that causality cannot be inferred and the findings of this study reflect the illness perceptions and health behaviours of study participants at the time of the study $(54,55)$. Illness perceptions often develop and change with time, and the nature of the relationship between illness perceptions and health behaviours is complex (56). The former may influence the latter but the latter may also feedback and influence the former $(24,57)$. Collecting data at a single point in time simplifies the complex relationship between illness perceptions and health behaviours and no claims can be made about whether certain illness perceptions caused certain health behaviours or vice versa.

Although self-reported measures of lifestyle behaviours are commonly used, they are thought to overestimate adherence to health behaviours $(58,59)$. Furthermore, recruiting participants from a hospital, and collecting data in the hospital using a researcher administered questionnaire in some instances, introduces social desirability in an adherent population, potentially leading to an overestimation of adherence to healthy lifestyle choices. 


\section{Conclusion}

This study found that statin-use was not on its own associated with the adoption of a low-fat diet. However, the odds of adopting a low-fat diet increased as statin control perceptions increased suggesting that statin-use and the adoption of healthy dietary choice were thought to work in unison to manage high cholesterol. The adoption of healthy exercise choices among study participants was rare and the prevalence of physical inactive was high. This highlights the need for public health interventions aimed at increasing physical activity for the prevention of non-communicable diseases and improvement of overall health. Finally, urban-dwellers were more likely to have adopted healthy dietary choices and to think about adopting exercise choices than semi-urban dwellers. This may demonstrate a growing awareness of negative future impacts of Westernised lifestyle behaviours in urban areas yet highlights the need for public health interventions in semi-urban areas in order to curtail the adoption of unhealthy lifestyle choices and diminish the rise of cardiovascular disease in Nigeria.

\section{List Of Abbreviations}

Cl: Confidence Interval; Cardiovascular disease: CVD; European Prospective Investigation of Cancer and Nutrition: EPIC; General Practice Physical Activity Questionnaire: GPPAQ; Human Immunodeficiency Viruses: HIV; The Revised Illness Perception Questionnaire: IPQ-R; Nigeria National Petroleum Corporation: NNPC; OR: Odds ratio; SD: Standard Deviation; S.E: Standard error; Statistical Package for the Social Sciences: SPSS; U: Mann Whitney test statistic; University of Calabar Teaching Hospital: UCTH; UK: United Kingdom; $X^{2}$ : Chi square test statistic; \%: percent.

\section{Declarations}

\section{Ethical approval and consent to participate}

This research received ethical approval from: Nigerian Institute of Medical Research (IRD/13/216); University of Calabar Teaching Hospital (UCTH/LR/DM/16); Nigerian National Petroleum Corporation (NNPC) Medical Services (GGM/11/12); and Leeds Institute of Health Sciences and Leeds Institute of Genetics, Health and Therapeutic and Leeds Institute of Molecular Medicine (LIHS/LIGHT/LIMM) joint ethics committee (HSLTLM/12/063R).

\section{Consent for publication}

Not applicable.

\section{Availability of data and materials}

The dataset used and/or analysed during this study is available from the corresponding author on reasonable request. 
The authors declare that they have no competing interests.

\section{Funding}

This study was part of a self-funded PhD project.

\section{Authors contributions}

$\mathrm{JC}, \mathrm{KH}, \mathrm{AH}$ were involved in the design and analysis of the study. AO facilitated access to and recruitment from the semi-urban site. All authors contributed to the final manuscript.

\section{Acknowledgments}

We would like to thank all the participants who took the time to complete the study questionnaire. We would also like to thank all the staff of NNPC and UCTH, particularly Dr Edwin Bako, Dr Victor Ansa and Dr Okon Essien.

\section{Authors information}

${ }^{1}$ Cambridge Institute of Public Health, School of Clinical Medicine, University of Cambridge, Cambridge, CB2 0SR. United Kingdom. ${ }^{2}$ Leeds Institute of Health Sciences, University of Leeds; Worsley Building (Rm 11.57), Clarendon Way, Leeds LS2 9NL, UK. ${ }^{3}$ Department of Internal Medicine, University of Calabar, Cross Rivers State, Calabar.

\section{References}

1.Maher D, Smeeth L, Sekajugo J. Health transition in Africa: practical policy proposals for primary care. Bulletin of the World Health Organization. 2010;88(12):943-8.

2.BeLue R, Okoror TA, Iwelunmor J, Taylor KD, Degboe AN, Agyemang C, et al. An overview of cardiovascular risk factor burden in sub-Saharan African countries: a socio-cultural perspective. Globalization and Health. 2009;5(1):10.

3.Ekpenyong C, NE U, Akpan E, Samson T. Double burden, non-communicable diseases and risk factors evaluation in sub-Saharan Africa: The Nigerian experience. European Journal of Sustainable Development. 2012;1(2):249-70.

4. World Health Organisation. Noncommunicable diseases (NCD) Country profiles, Nigeria. 2018 https://www.who.int/nmh/countries/nga_en.pdf?ua = 1. 'Accessed' 16 Jul 2019.

5.Awosan J. Currents of Thought in African Sociology and the Global Community: How to Understand Research Findings in the Context of Sociological Perspectives. Florida: Universal Publishers; 2009. 
6.Essien OE, Andy J, Ansa V, Otu AA, Udoh A. Coronary artery disease and the profile of cardiovascular risk factors in South South Nigeria: a clinical and autopsy study. Cardiology Research and Practice. 2014;2014.

7.Mendis S, Puska P, Norrving B, Organization WH. Global atlas on cardiovascular disease prevention and control: Geneva: World Health Organization; 2011.

8.Okpechi IG, Chukwuonye II, Tiffin N, Madukwe 00, Onyeonoro UU, Umeizudike TI, et al. Blood pressure gradients and cardiovascular risk factors in urban and rural populations in Abia State South Eastern Nigeria using the WHO STEPwise approach. PLOS ONE. 2013;8(9):e73403.

9.Sani MU, Wahab KW, Yusuf BO, Gbadamosi M, Johnson OV, Gbadamosi A. Modifiable cardiovascular risk factors among apparently healthy adult Nigerian population-a cross sectional study. BMC Research Notes. 2010;3(1):11.

10.National Institutes of Health. National heart, lung and blood institute Third Report of the National Cholesterol Education Program (NCEP) Expert Panel on Detection, Evaluation, and Treatmentof High Blood Cholesterol in Adults (Adult Treatment Panel III) Final Report. Circulation. 2002;106(25):3143-421.

11.National Institute for Health and Care Excellence. Lipid Modification: Cardiovascular Risk Assessment and the Modification of Blood Lipids for the Primary and Secondary Prevention of Cardiovascular Disease. Clinical guideline [CG67]. 2014 https://www.nice.org.uk/guidance/cg67. 'Accessed' 16 Jul 2019.

12. World Health Organisation. Prevention of cardiovascular disease. 2007 https://www.who.int/cardiovascular_diseases/guidelines/Full\%20text.pdf. 'Accessed' 16 Jul 2019.

13.Kajinami K, Takekoshi N, Saito Y. Pitavastatin: efficacy and safety profiles of a novel synthetic HMGCoA reductase inhibitor. Cardiovascular Drug Reviews. 2003;21(3):199-215.

14.Kastelein JJ. Dyslipidaemia in perspective. The Lancet. 2014;384(9943):566-8.

15.Opie LH, Gersh BJ. Drugs for the Heart E-Book. Philadelphia: Elsevier Health Sciences; 2011.

16.Mann DM, Natarajan S. Inverse relationship between lipid-lowering drugs and saturated fat intake in US adults. Cardiovascular Drugs and Therapy. 2007;21(2):109-15.

17.Mann DM, Allegrante JP, Natarajan S, Montori VM, Halm EA, Charlson M. Dietary indiscretion and statin use. Mayo Clinic Proceedings. 2007;82(8):951-3.

18.Redberg RF. Statins and weight gain. JAMA internal medicine. 2014;174(7):1046.

19.Sugiyama T, Tsugawa Y, Tseng C-H, Kobayashi Y, Shapiro MF. Different time trends of caloric and fat intake between statin users and nonusers among US adults: gluttony in the time of statins? JAMA Internal Medicine. 2014;174(7):1038-45. 
20.Lytsy P, Burell G, Westerling R. Cardiovascular risk factor assessments and health behaviours in patients using statins compared to a non-treated population. International Journal of Behavioral Medicine. 2012;19(2):134-42.

21.Chiuve SE, McCullough ML, Sacks FM, Rimm EB. Healthy lifestyle factors in the primary prevention of coronary heart disease among men: benefits among users and nonusers of lipid-lowering and antihypertensive medications. Circulation. 2006;114(2):160-7.

22.Cobb MM, Teitelbaum HS, Breslow JL. Lovastatin efficacy in reducing low-density lipoprotein cholesterol levels on high-vs low-fat diets. JAMA. 1991;265(8):997-1001.

23.Hunninghake DB, Stein EA, Dujovne CA, Harris WS, Feldman EB, Miller VT, et al. The efficacy of intensive dietary therapy alone or combined with lovastatin in outpatients with hypercholesterolemia. New England Journal of Medicine. 1993;328(17):1213-9.

24.Pickett S, Allen W, Franklin M, Peters RM. Illness beliefs in African Americans with hypertension. Western Journal of Nursing Research. 2014;36(2):152-70.

25.Coutu M-F, Dupuis G, D'Antono B, Rochon-Goyer L. Illness representation and change in dietary habits in hypercholesterolemic patients. Journal of Behavioral Medicine. 2003;26(2):133-52.

26.Diefenbach MA, Leventhal $\mathrm{H}$. The common-sense model of illness representation: Theoretical and practical considerations. Journal of Social Distress and the Homeless. 1996;5(1):11-38.

27.Ross S, Walker A, MacLeod MJ. Patient compliance in hypertension: role of illness perceptions and treatment beliefs. Journal of Human Hypertension. 2004;18(9):607-13.

28.Rosenstock IM. Historical origins of the health belief model. Health Education Monographs. 1974;2(4):328-35.

29.Leventhal H, Brissette I, Leventhal EA. The common-sense model of self-regulation of health and illness. In: Cameron LD, Leventhal H, editors. The Self-Regulation of Health and Behaviour. USA: Routledge; 2003. p. 42-65.

30.Anosike F, Mammah C, Ojo J, Ugbede N, Egwuda E, Azuwuike M, et al. The best of Nigeria. The Nigerian Country Book: New windows of opportunities. Lagos, Nigeria: 1st October Publications LTD; 2009.

31.Ansa V, Oyo-Ita A, Essien O. Perception of ischaemic heart diease, knowledge of and attitude to reduction of its risk factors. East African Medical Journal. 2007;84(7):318-23.

32.Muhammad S, Sani MU, Okeahialam BN. Cardiovascular disease risk factors among HIV-infected Nigerians receiving highly active antiretroviral therapy. Nigerian Medical Journal. 2013;54(3):185-90. 
33.Bingham SA, Welch AA, McTaggart A, Mulligan AA, Runswick SA, Luben R, et al. Nutritional methods in the European prospective investigation of cancer in Norfolk. Public Health Nutrition. 2001;4(3):847-58.

34.University of Cambridge, European Prospective Investigation of Cancer (EPIC). EPIC-Norfolk: nutritional methods- Food Frequency Questionnaire download. 2014

http://www.srl.cam.ac.uk/epic/nutmethod/FFQii.shtml. 'Accessed' 16th May 2019.

35.Curry SJ, Kristal AR, Bowen DJ. An application of the stage model of behavior change to dietary fat reduction. Health Education Research. 1992;7(1):97-105.

36.Department of Health and Social Care. General Practive Physical Activity Questionnaire. 2013 https://www.gov.uk/government/publications/general-practice-physical-activity-questionnaire-gppaq. 'Accessed' 16th May 2019.

37.Moss-Morris R, Weinman J, Petrie K, Horne R, Cameron L, Buick D. The revised illness perception questionnaire (IPQ-R). Psychology \& Health. 2002;17(1):1-16.

38.Hsiao C-Y, Chang C, Chen C-D. An investigation on illness perception and adherence among hypertensive patients. The Kaohsiung Journal of Medical Sciences. 2012;28(8):442-7.

39.Falola T. Culture and customs of Nigeria. Westport, USA: Greenwood Publishing Group; 2001.

40.Champion VL. Instrument development for health belief model constructs. Advances in Nursing Science. 1984;6(3):73-85.

41.Abraham C, Sheeran P. The health belief model. In: CONNER M, NORMAN P, editors. Predicting Health Behaviour. 2 ed. Berkshire, England: Open University Press; 2005. p. 28-80.

42.Field A. Discovering statistics using SPSS: and sex drugs and rock ' $n$ ' roll. 3 ed. London: Sage publications; 2009.

43.Lofgren I, Greene G, Schembre S, Delmonico MJ, Riebe D, Clark P. Comparison of diet quality, physical activity and biochemical values of older adults either reporting or not reporting use of lipid-lowering medication. The Journal of Nutrition, Health \& Aging. 2010;14(2):168-72.

44.Nigerian Heart Foundation, Federal Ministry of Health, World Health Organisation. Health behaviour monitor among Nigerian adult population. 2003

https://www.who.int/ncds/surveillance/steps/2003_STEPS_Report_Nigeria.pdf. 'Accessed' 16 Jul 2019.

45.Abubakari A, Bhopal R. Systematic review on the prevalence of diabetes, overweight/obesity and physical inactivity in Ghanaians and Nigerians. Public Health. 2008;122(2):173-82.

46.The Lancet Diabetes Endocrinology. Healthy lifestyle guidelines-are they good enough? The lancet Diabetes \& endocrinology. 2014;2(10):765. 
47.USAID, UKaid, UNICEF. National Nutrition and Health Survey (NNHS) 2018: Report-The Nutrition and Health Situation in Nigeria. 2018 https://www.unicef.org/nigeria/media/2181/file/Nigeria-NNHS2018.pdf. 'Accessed' 2nd Aug 2019.

48. Hallal PC, Andersen LB, Bull FC, Guthold R, Haskell W, Ekelund U, et al. Global physical activity levels: surveillance progress, pitfalls, and prospects. The Lancet. 2012;380(9838):247-57.

49.Ulasi II, ljoma CK, Onodugo OD. A community-based study of hypertension and cardio-metabolic syndrome in semi-urban and rural communities in Nigeria. BMC Health Services Research. 2010;10(71).

50.Ejim E, Okafor C, Emehel A, Mbah A, Onyia U, Egwuonwu T, et al. Prevalence of cardiovascular risk factors in the middle-aged and elderly population of a Nigerian rural community. Journal of Tropical Medicine. 2011;2011.

51.Dahiru T, Ejembi C. Clustering of cardiovascular disease risk-factors in semi-urban population in Northern Nigeria. Nigerian Journal of Clinical Practice. 2013;16(4).

52.Makusidi MA, Liman HM, Yakubu A, Isah M, Jega R, Adamu H, et al. Prevalence of non-communicable diseases and its awareness among inhabitants of Sokoto metropolis: Outcome of a screening program for hypertension, obesity, diabetes mellitus and overt proteinuria. Arab Journal of Nephrology and Transplantation. 2013;6(3):189-91.

53.Unwin N, Setel P, Rashid S, Mugusi F, Mbanya J-C, Kitange H, et al. Noncommunicable diseases in subSaharan Africa: where do they feature in the health research agenda? Bulletin of the World Health organization. 2001;79:947-53.

54.Bryman A. Social Research Methods. Oxford: Oxford University Press; 2008.

55.Walter M. Social Research Methods. Australia Oxford University Press; 2012.

56.Stack RJ, Bundy C, Elliott RA, New JP, Gibson JM, Noyce PR. Patient perceptions of treatment and illness when prescribed multiple medicines for co-morbid type 2 diabetes. Diabetes, Metabolic Syndrome and Obesity: Targets and Therapy. 2011;4:127-35.

57.Salovey P, Rothman AJ. Social Psychology of Health: Key Readings. New York and Hove: Psychology Press; 2003.

58.Dunbar-Jacob J, Schlenk EA, Caruthers D. Adherence in the management of chronic disorders. In: Christensen AJ, Antoni MH, editors. Chronic Physical Disorders: Behavioral Medicine's Perspective. Oxford: Blackwell Publishers; 2002. p. 69-82.

59.Hekler EB, Lambert J, Leventhal E, Leventhal H, Jahn E, Contrada RJ. Commonsense illness beliefs, adherence behaviors, and hypertension control among African Americans. Journal of Behavioral Medicine. 2008;31(5):391-400. 


\section{Tables}

Table 1: Characteristics of the study sample 


\begin{tabular}{|c|c|c|c|}
\hline Variables & $\begin{array}{l}\text { Statin users } \\
\mathrm{n}=78(52.7 \%)\end{array}$ & $\begin{array}{l}\text { Non-statin users } \\
n=70(47.3 \%)\end{array}$ & $\begin{array}{c}\text { Overall } \\
\mathrm{n}=148(100 \%)\end{array}$ \\
\hline Mean age (years) (SD) & $52.68(10.45)$ & $53.16(11.88)$ & $52.91(11.11)$ \\
\hline $20-29$ & $0(0)$ & $2(2.9)$ & $2(1.4)$ \\
\hline $30-39$ & $9(11.5)$ & $4(5.7)$ & $13(8.8)$ \\
\hline $40-49$ & $21(26.9)$ & $20(28.6)$ & $41(27.7)$ \\
\hline $50-59$ & $27(34.6)$ & $25(35.7)$ & $52(35.1)$ \\
\hline $60-69$ & $19(24.4)$ & $13(18.6)$ & $32(21.6)$ \\
\hline $70-79$ & $1(1.3)$ & $4(5.7)$ & $5(3.4)$ \\
\hline 80-89 & $1(1.3)$ & $2(1.4)$ & $3(2.0)$ \\
\hline \multicolumn{4}{|l|}{ Gender } \\
\hline Male & $35(44.9)$ & $29(41.4)$ & $64(43.2)$ \\
\hline Female & $43(55.1)$ & $41(58.6)$ & $84(56.8)$ \\
\hline \multicolumn{4}{|l|}{ Site of recruitment } \\
\hline Semi-urban & $39(50.0)$ & $43(61.4)$ & $82(55.4)$ \\
\hline Urban & $39(50.0)$ & $27(38.6)$ & $66(44.6)$ \\
\hline \multicolumn{4}{|l|}{ Marital status } \\
\hline Single & $6(7.7)$ & $6(8.6)$ & $12(8.1)^{*}$ \\
\hline Married & $62(79.5)$ & $53(75.7)$ & $115(77.7)^{*}$ \\
\hline Separated/ divorced & $7(9.0)$ & $1(1.4)$ & $8(5.4)^{*}$ \\
\hline Widowed & $3(3.8)$ & 9 (12.9) & $12(8.1)^{*}$ \\
\hline Unknown & $0(0)$ & $1(1.4)$ & $1(0.7)$ \\
\hline \multicolumn{4}{|l|}{ Education } \\
\hline Primary or less & $21(26.9)$ & $26(37.1)$ & $47(31.8)$ \\
\hline Secondary level & $11(14.1)$ & $5(7.1)$ & $16(10.8)$ \\
\hline Tertiary level & $44(56.4)$ & 37 (52.9) & $81(54.7)$ \\
\hline Unknown & $2(2.6)$ & $2(2.9)$ & $4(2.7)$ \\
\hline
\end{tabular}




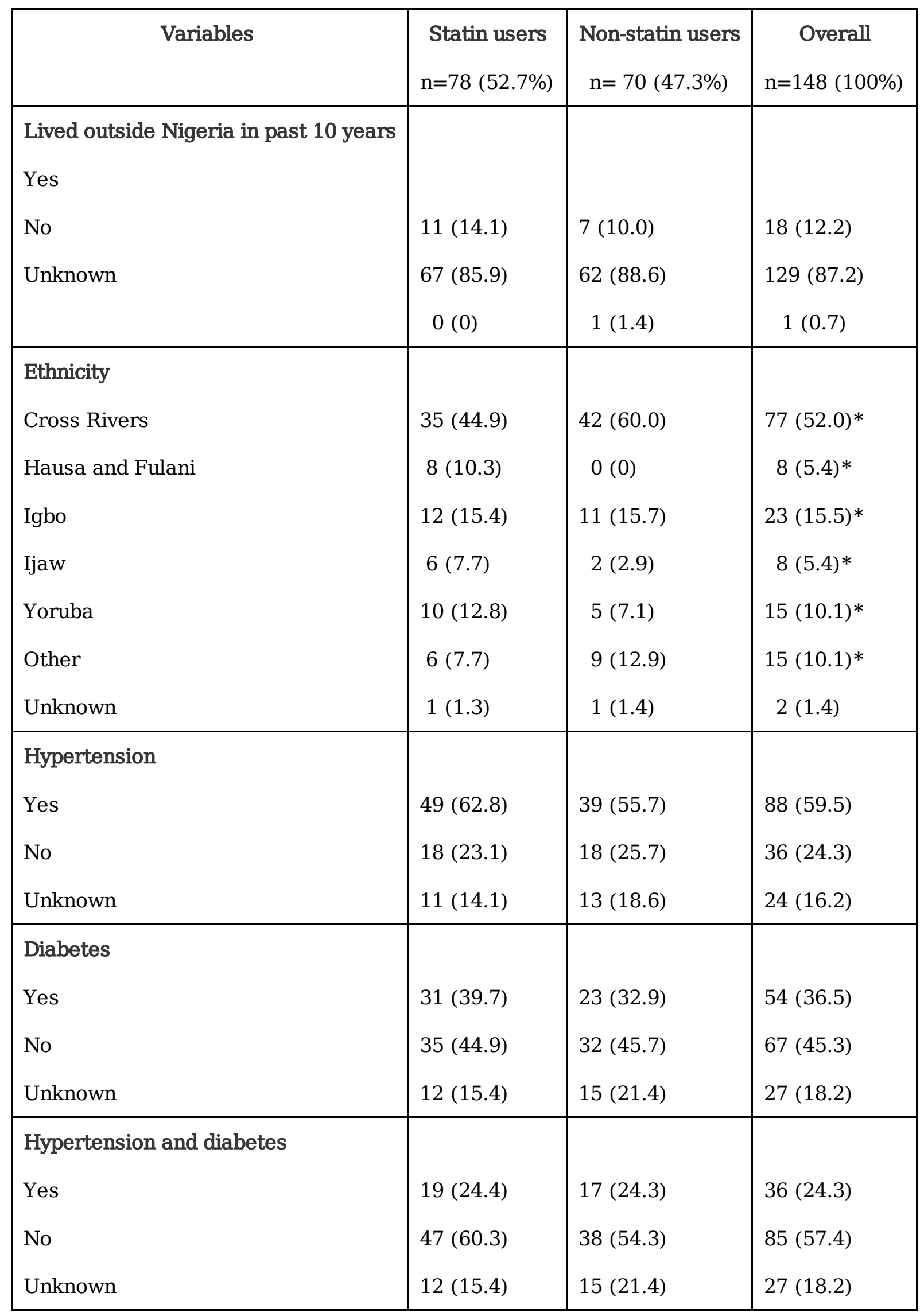

$* p<0.05$ 
Table 2: Dietary patterns

Page 22/27 


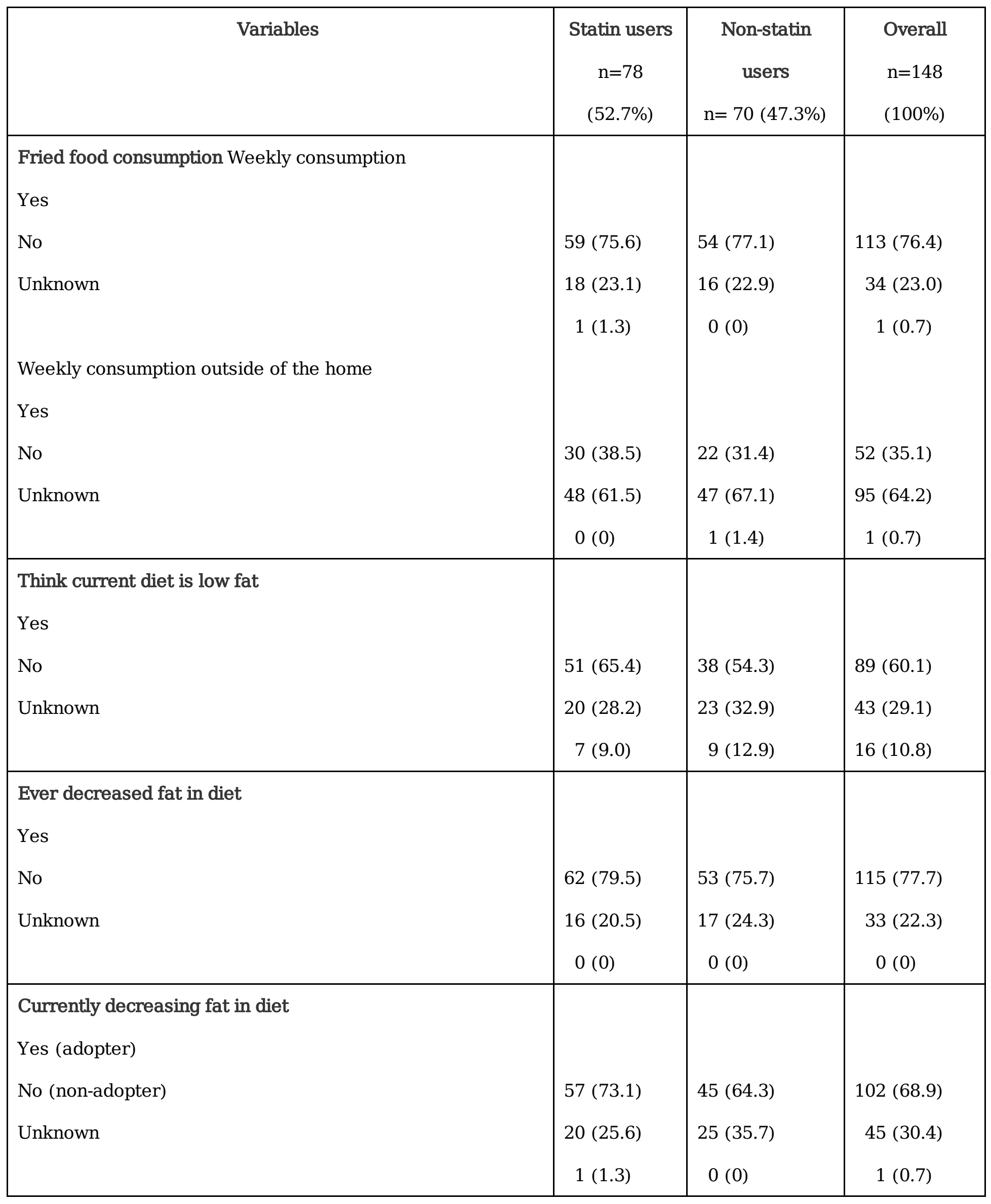




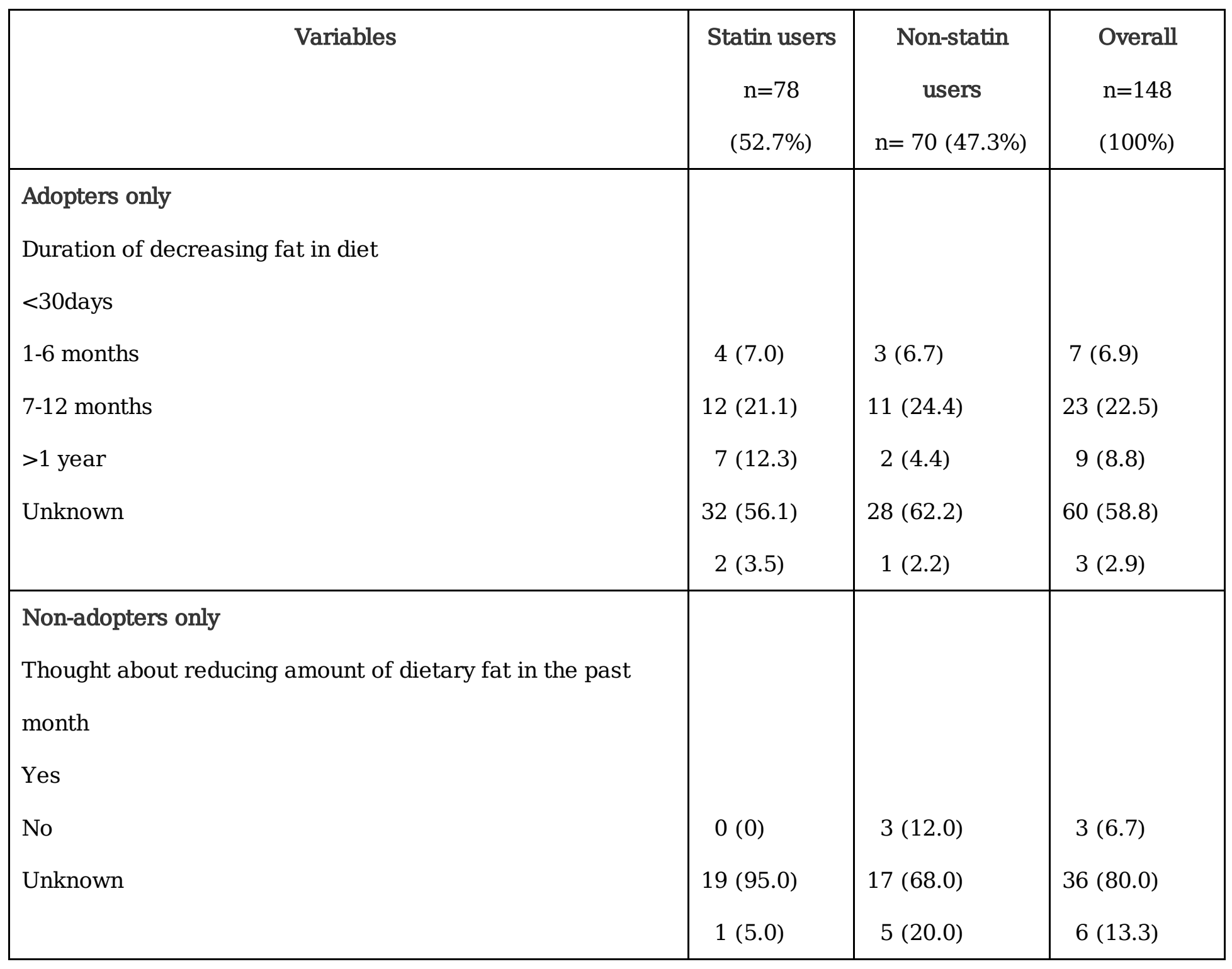

Table 3: Exercise patterns 


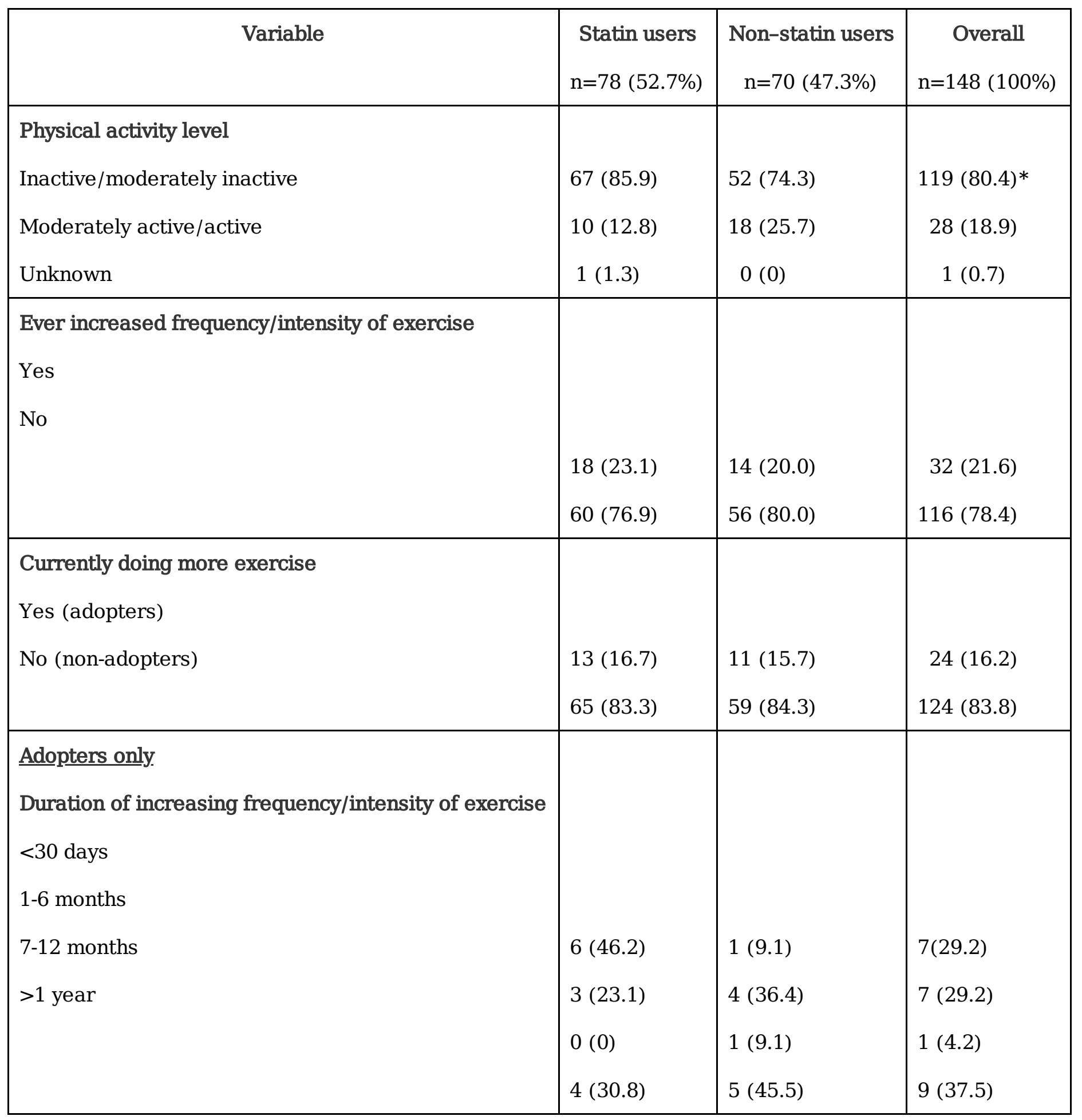




\begin{tabular}{|l|c|c|c|}
\hline \multicolumn{1}{|c|}{ Variable } & $\begin{array}{c}\text { Statin users } \\
\mathrm{n}=78(52.7 \%)\end{array}$ & $\begin{array}{c}\text { Non-statin users } \\
\mathrm{n}=70(47.3 \%)\end{array}$ & $\mathrm{n}=148(100 \%)$ \\
\hline Non-adopters only. & & & \\
Thought about increasing frequency or & & & \\
intensity of exercise in the past month & $13(20.0)$ & $16(27.1)$ & $29(23.4)$ \\
Yes & $52(80.0)$ & $40(71.2)$ & $94(75.8)$ \\
No & $0(0)$ & $1(1.7)$ & $1(0.8)$ \\
\hline Unknown & & & \\
\hline
\end{tabular}

$* \mathrm{p} \leq 0.05$

Table 4: Perceptions of high cholesterol

\begin{tabular}{|c|c|c|c|}
\hline Variables & $\begin{array}{c}\text { Statin } \\
\text { users } \\
\mathrm{n}=75 \text { (SD) }\end{array}$ & $\begin{array}{c}\text { Non-statin } \\
\text { users } \\
\mathrm{n}=64 \text { (SD) }\end{array}$ & $\begin{array}{l}\text { Overall } \\
\mathrm{n}=139 \text { (SD) }\end{array}$ \\
\hline Mean perceived timeline acute/chronic & $2.12(0.67)$ & $2.31(0.70)$ & $2.21(0.66)$ \\
\hline Mean perceived timeline cyclical & $3.16(0.84)$ & $3.18(0.85)$ & $3.17(0.84)$ \\
\hline Mean perceived consequences & $2.94(0.68)$ & $2.94(0.65)$ & $2.94(0.66)$ \\
\hline Mean perceived personal control & $3.87(0.68)$ & $3.84(0.58)$ & $3.85(0.62)$ \\
\hline Mean perceived statin control & $3.78(0.66)$ & $3.57(0.59)$ & $3.68(0.64) * *$ \\
\hline Mean perceived emotional response & $2.95(0.95)$ & $3.03(0.93)$ & $2.99(0.94)$ \\
\hline Mean perceived illness coherence & $3.24(1.13)$ & $3.19(1.13)$ & $3.22(1.12)$ \\
\hline Total perceived biomedical cause ${ }^{€}$ & $13.99(2.90)$ & $14.06(3.91)$ & $14.02(3.39)$ \\
\hline Total perceived spiritual cause ${ }^{€}$ & $7.08(3.37)$ & $6.55(2.98)$ & $6.83(3.20)$ \\
\hline Total perceived lifestyle cause ${ }^{\$}$ & $23.51(4.35)$ & $23.97(4.86)$ & $23.72(4.58)$ \\
\hline
\end{tabular}

${ }^{* *} \mathrm{p} \leq 0.01, €$ this sub-scale has 5 items and scores range between 5-25, $€$ this subscale has 3 items and scores range between 3-15, \$ this subscale has 8 items and scores range between 8-40. 
Table 5: Perceptions of future risk of cardiovascular disease

\begin{tabular}{|l|c|c|c|}
\hline \multicolumn{1}{|c|}{ Variable } & Statin & Non-statin & Overall \\
& users & users & \\
& $\mathrm{n}=71(\mathrm{SD})$ & $\mathrm{n}=62(\mathrm{SD})$ & $\mathrm{n}=133(\mathrm{SD})$ \\
\hline Perceived susceptibility & $2.44(0.84)$ & $2.25(0.80)$ & $2.35(0.83)$ \\
Perceived severity & $3.10(0.68)$ & $2.86(0.75)$ & $2.99(0.72)^{*}$ \\
Perceived benefits of statins & $3.88(0.67)$ & $3.72(0.73)$ & $3.80(0.70)$ \\
Perceived benefits of healthy lifestyle choices & $4.00(0.65)$ & $4.01(0.66)$ & $4.00(0.65)$ \\
Perceived barriers to statins & $2.31(0.72)$ & $2.56(0.79)$ & $2.43(0.76) *$ \\
Perceived barriers to healthy lifestyle choices & $2.76(0.76)$ & $2.69(0.74)$ & $2.73(0.75)$ \\
\hline
\end{tabular}

$* \mathrm{p} \leq 0.05$

Table 6: Logistic regression model for the adoption of a low-fat diet

\begin{tabular}{|l|c|l|l|l|l|l|}
\hline \multicolumn{1}{|c|}{ Variables } & B & S.E & Wald & P value & OR & \multicolumn{1}{c|}{ 95\%CI } \\
\hline Statin status (statin-use) & -0.20 & 0.46 & 0.20 & 0.66 & 0.82 & $0.34-1.96$ \\
\hline Gender (Male) & 0.45 & 0.48 & 0.87 & 0.35 & 1.56 & $0.61-4.00$ \\
\hline Research site(semi-urban) & -1.51 & 0.52 & 8.90 & $0.003^{* *}$ & $0.21^{\$}$ & $0.08-0.59^{\$}$ \\
\hline Physical activity level (inactive/moderately inactive) & -0.20 & 0.60 & 0.11 & 0.74 & 0.82 & $0.25-2.66$ \\
\hline Statin control of high cholesterol & 0.85 & 0.36 & 5.60 & $0.018^{* *}$ & 2.33 & $1.16-4.69$ \\
\hline Barriers to statins-use to prevent CVD & -0.33 & 0.30 & 1.24 & 0.27 & 0.72 & $0.40-1.29$ \\
\hline Perceived severity of CVD & 0.41 & 0.38 & 1.19 & 0.28 & 0.28 & $0.72-3.16$ \\
\hline
\end{tabular}

${ }^{*} \mathrm{p} \leq 0.05, * * \mathrm{p} \leq 0.01, \$$ Inverted version of these values i.e. 1 divided by the value is presented in the text to make interpretation easier. $\mathrm{n}=128$. 